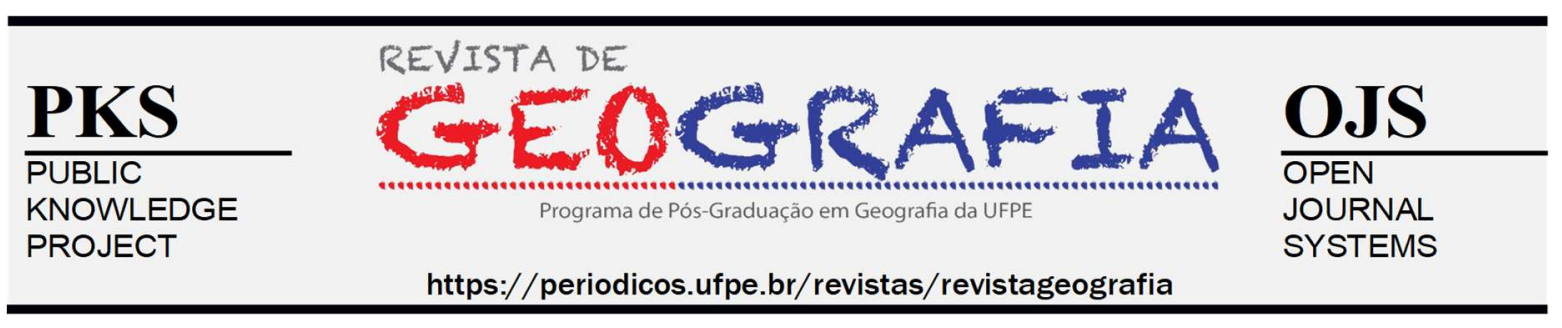

\title{
CAPACIDADE DE INFILTRAÇÃO EM NEOSSOLO FLÚVICO E CAMBISSOLO HÁPLICO NO SEMIÁRIDO PERNAMBUCANO
}

\author{
Cleuma Christir da Silva Almeida ${ }^{1}$, Victor Cassimiro Piscoya ${ }^{2}$, \\ Thyêgo Nunes Alves Barreto ${ }^{3}$, Fernando Cartaxo Rolim Neto ${ }^{4}$
}

\begin{abstract}
${ }^{1}$ Mestre em Eng. Ambiental - UFRPE; Graduação em Eng. Florestal - UFRPE. E-mail: cleumachristir@gmail.com

${ }^{2}$ Doutorado em Agronomia - UFRPE; Eng. Florestal - UNAP (PERU). E-mail: victorcasimiropiscoya@gmail.com

${ }^{3}$ Doutorado Ciência Florestal-UFRPE; Mestrado em Ciências Florestais - UFRPE; Eng. Florestal-UFRPE. E-mail: thyego_nunes@gmail.com

${ }^{4}$ Doutorado em Agronomia - UFV; Eng. Agronomia - UFPB. E-mail: fernandocartaxo@yahoo.com.br
\end{abstract}

Artigo recebido em 14/08/2019 e aceito em 25/11/2019

Resumo: Estudos relacionados a dinâmica da água no solo do semiárido torna-se importante por se tratar de áreas com grande escassez hídrica, onde a infiltração de água no solo influencia diretamente na dinâmica do solo, rendimento das culturas e otimização do uso da água. $\mathrm{O}$ objetivo geral da pesquisa foi avaliar a capacidade de infiltração básica do Neossolo Flúvico e do Cambissolo Háplico no semiárido Pernambucano, em períodos chuvoso e seco, através dos modelos equação de Horton e Kostiakov utilizando o método do infiltrômetro com anéis concêntricos do anel duplo. As características físicas dos solos estudados, foram classificados ambos com textura franco arenosa, com semelhanças na composição granulométrica. A capacidade de infiltração inicial foi alta com valor de $39,75 \mathrm{~cm} . \mathrm{h}^{-1}$ para o Cambissolo, comparada com a do Neossolo para o período seco de 23,44 $\mathrm{cm} . \mathrm{h}^{-1}$, assim como para o Neossolo $24,09 \mathrm{~cm} \cdot \mathrm{h}^{-1}$ e Cambissolo $24,84 \mathrm{~cm} \cdot \mathrm{h}^{-1}$ no período chuvoso. A capacidade de infiltração do Cambissolo Háplico se mostrou superior aos demais tratamentos, podendo estar relacionado a evolução estrutural deste solo em compararação ao Neossolo Flúvico. Tanto a equação de Kostiakov quanto a de Horton podem ser usados para estimar a taxa potencial de infiltração do solo in situ no semiárido.

Palavras-chave: Infiltração, Modelos de Horton e Kostiakov, Solos do semiárido.

\section{INFILTRATION CAPACITY IN FLUBIC NEOSSLE AND HAPLESS CAMBISOL IN THE SEMI-ARID PERNAMBUCO}

Abstract: Studies related to water dynamics, without soil to make semi-arid, are important because they are areas with great water scarcity, where a infiltration of water does not only influence directly the soil dynamics, crop yield and optimization of water use. The general objective of the research was to evaluate the basic infiltration capacity of the Fluovian Neossolo and the Hapless Cambisol without semiarid Pernambuco, in rainy and dry periods, using the Horton and Kostiakov equation models, the infiltrator method with concentric double ring rings. The physical characteristics of the studied soils were classified with both sandy loam texture, with terms in the granulometric composition. The initial infiltration capacity was high with a value of $39.75 \mathrm{~cm} . \mathrm{h}^{-1}$ for the Cambisols, compared with a Neosol for the dry period of $23.44 \mathrm{~cm} . \mathrm{h}^{-1}$, as well as for the Neosol 24.09 $\mathrm{cm} \cdot \mathrm{h}^{-1}$ and Cambissolo $24.84 \mathrm{~cm} \cdot \mathrm{h}^{-1}$ in the rainy season. The infiltration capacity of the Hapol Cambisol showed to be superior to the other treatments, being able to be related to a structural development of this soil in 
comparison to the Flossic Neosol. Both the Kostiakov and Horton equations can be used to estimate the potential rate of soil infiltration in situ without semiarid.

Keywords: Infiltration, Horton and Kostiakov models, Semi-arid soils.

\section{INTRODUÇÃO}

A infiltração é o processo de entrada descendente de água no solo (HILLEL, 1980), que chega à superfície e entra no mesmo (GREGORY et al., 2005). É um parâmetro hidrológico que separa a água em escoamento superficial e recarga (SRINIVASAN \& POONGOTHAI, 2013). É difícil de ser medida com precisão, tornando-se importante o monitoramento contínuo (CECÍLIO et al., 2003; DIAMOND e SHANLEY, 2003).

A infiltração do solo ou capacidade de infiltração é conhecida como velocidade de infiltração no solo que passa pelas camadas, através dos poros, sob a ação da gravidade, controlada por fatores do solo, ficando armazenada temporariamente, tornando-a disponível para o crescimento e desenvolvimento das plantas e dos organismos do solo (JOHNSON, 1963; PINTO et al., 1976; GREGORY et al., 2005; LIU et al., 2011).

A infiltração alcança uma determinada velocidade, no início da chuva ou irrigação, com tendência a diminuir gradativamente com o tempo, alcançando um valor mínimo e constante, passando a ser conhecida como velocidade básica de infiltração - VIB (REICHARDT, 1987). Existem vários métodos para determinação da VIB tais como: infiltrômetros de anéis concêntricos, aspersores ou simuladores de chuvas, entrada-saída de água no sulco, método do balde sem fundo, entre outros (TOUMA \& ALBERGEL, 1992; BERNARDO, 1995; LIU et al., 2011; ZONTA et al., 2012; BAGARELLO et al., 2014; MESHGI \& CHUI, 2014; ALAGNA et al, 2016; DUNKERLEY, 2017; OLORUNFEMI \& FASINMIRIN, 2017).

Alguns fatores interferem na magnitude da taxa de infiltração, como é o caso do uso e ocupação do solo, pisoteio do gado em pastagens, o relevo, o tipo de cobertura e densidade vegetal, características físicas e estrutura do solo, bem como a precipitação local, umidade natural do solo e a condutividade hidráulica do solo, hidrofobicidade, além da ação de microorganismos, espaços vázios feitos por animais, insetos e até a decomposição das raízes (JOHNSON, 1963; PINTO et al., 1976; CARDURO \& DORFMAN, 1988; THUROW et al., 1988; BERNARDO, 1995; BRANDÃO et al., 2006; PHILIPS, 2011; ALMEIDA et al., 2014; LIMA et al., 2015). 
A infiltração pode ser influenciada pela maior porcentagem de areia do solo (MAZAHERI \& MAHMOODABADI, 2012). Os solos de textura grossa, arenosa, possuem em geral, maior número de macro poros o que facilitaria a infiltração no mesmo, diferentemente dos solos densos (BRANDÃO et al., 2006). O número de poros e os formatos podem influenciar na infiltração do solo (GONÇALVES \& MORAES, 2012).

A intensidade e impacto da gota das chuvas são outros fatores que parece influir negativamente na infiltração do solo, ocasionando em uma menor velocidade da mesma (MORIN \& VAN WINKEL, 1996; LIU et al., 2011; CHANDRAKANT et al., 2015).

A diferenciação do comportamento da velocidade de infiltração também pode diferir, segundo Daimond \& Shanley (2003), entre as estações, onde no verão a infiltração se mostra normalmente superior.

A matéria orgânica é outro atributo do solo fundamental para a qualidade do solo, pois altera a agregação do solo, controlando a lixiviação e disponibilidade de água para as espécies vegetais (FRANZLEBBERS, 2002).

Além dos fatores ambientais e as características do solo, a redução da infiltração parece estar relacionada ao uso do solo, onde áreas com cultivos se mostram limitadoras do aumento da porosidade local e da infiltração, devido as arações mecanizadas que produzem um aumento da densidade do solo, compactação do solo e consequentemente um maior escoamento superficial (HILLEL, 1982; VOORHES \& LINDSTROM, 1984; BLACKWELL et al., 1985; ALLEGRE et al., 1986; HARTGE, 1988; THUROW et al., 1988; PAGLIAI et al., 2004; CUNHA et al., 2015).

Mancuso et al. (2014) e Osuji et al. (2010) apontaram que os solos com áreas de arbustos em pousio em comparação as terras aráveis apresentarma taxas de infiltração superiores. Semelhante resultado foi encontrado por Zonta et al. (2012), com simulador de chuva em Cambissolo Háplico Tb distrófico, onde apontaram que a taxa de infiltração foi reduzida em até $75 \%$ para condições de solo sem cobertura, quando comparado ao solo com cobertura.

Outro fator que parece limitar a infiltração do solo é o pisoteio do gado em pastagens, onde a pressão de pastejo remove arbustos, ervas e controla grande quantidade de matéria orgânica na superfície do solo (THUROW et al., 1988).

Outro ponto ligado a redução da infiltração e aceleração do escoamento superficial são as queimadas dos solos (EBEL \& MOODY, 2016). As queimadas elevam a temperatura do 
solo, durante e após as mesmas, alterando as características físicas do solo, como a redução da capacidade de absorção de água, sendo explicada pela retirada da biomassa e pelo desenvolvimento da repelência à água causada por elementos hidromórficos voláteis presentes no material combustível, (COSTA \& RODRIGUES, 2015; OLORUNFEMI \& FASINMIRIN, 2017). Tais elementos hidromórficos, são oriundos da deposição ou decomposição dos compostos orgânicos hidrofóbicos, seja incêndios, $\mathrm{pH}$ elevado, entre outros, com ocorrência normalmente em clima seco e solo arenoso (VOGELMANN et al., 2015).

A compreensão de variáveis físicas do solo, como a velocidade de infiltração, pode ser importante para o entendimento das causas da variabilidade na produção das cultura, por isso, a análise estatística é de suma importância para auxiliar na tomada de decisão. Para tal, existem alguns modelos utilizados para a previsão de infiltração de água no solo, que são o de Horton e Kostiakov utilizados em estudos com boas predições, como os estudos desenvolvidos por Abdulkadir et al. (2011) e Liu et al. (2011).

O objetivo do presente trabalho foi avaliar o processo de infiltração de um Neossolo Flúvico e de um Cambissolo Háplico em ambiente Semiárido nos períodos chuvoso e seco, através das equações de Horton e Kostiakov.

\section{METODOLOGIA}

O estudo foi desenvolvido na bacia hidrográfica do riacho Jacu, região do Alto Sertão do Pajeú, nos domínios da bacia hidrográfica do rio Pajeú, no município de Serra Talhada PE, cujo acesso se dá pela rodovia estadual PE 390 no km 20, na região da Serra da Lagartixa, nos limites entre os municípios de Serra Talhada e Floresta, entre as coordenadas geográficas $35^{\circ} 24^{\prime} 00^{\prime}$ de longitude Oeste e $08^{\circ} 08^{\prime} 00^{\prime \prime}$ de latitude Sul. Distante de Recife $(515 \mathrm{~km})$, porção norte do Estado de Pernambuco (CPRM, 2005).

O clima da região, de acordo com a classificação de Köppen, enquadra-se no tipo Bwh, denominado semiárido, quente e seco, com chuvas de verão-outono, com pluviosidade média anual de 475,57 $\mathrm{mm} \mathrm{ano}^{-1}$ para o período entre 2010 e 2015 (APAC, 2017). O período chuvoso inicia-se no mês de dezembro e termina em abril.

Foram obtidas as médias da precipitação acumulada para o ano estudado de 2016, de $237,8 \mathrm{~mm}$ para todo o ano, com uma distribuição irregular das chuvas. A maior precipitação foi observada no mês de janeiro $(99,66 \mathrm{~mm})$ com precipitações de menor intensidade nos meses de julho, agosto, outubro e novembro (APAC, 2017). 
O experimento ocorreu em dois períodos do ano, sendo um no período seco e outro no chuvoso, em áreas com Neossolo Flúvico (Melo et al., 2008) e Cambissolo Háplico (Piscoya, 2012), resultando em quatro tratamentos, a saber: T1 - Cambissolo Háplico no período chuvoso; T2 - Cambissolo Háplico no período seco; T3 - Neossolo Flúvico no período chuvoso; T4 - Neossolo Flúvico no período seco. A coleta de dados para o período chuvoso foi em março de $2016(15,62 \mathrm{~mm})$, sendo a coleta no período seco em novembro, sem precipitação (APAC, 2017).

Os dois tipos de solos usados nesta pesquisa encontram-se inseridos na bacia hidrográfica semiárida do Jacu, com área de $2,10 \mathrm{~km}^{2}$ e perímetro de $6,50 \mathrm{~km}$, apresentando cursos d'água com drenagem de terceira ordem (PISCOYA, 2012). Os solos estudados foram caracterizados como sendo de textura franco arenosa, com semelhanças na composição granulométrica. A predominância de areia nas três profundidades do solo $(0-10 \mathrm{~cm} ; 10-20 \mathrm{~cm}$; $>20 \mathrm{~cm}$ ) foram semelhantes, tanto no Cambissolo Háplico quanto no Neossolo Flúvico, porém com um ligeiro decréscimo neste último. A predominância de areia nas granulometrias dos solos é consequência da derivação de sedimentos aluviais, em função das suas localizações nas partes mais baixas da bacia (tabela 1).

Tabela 1 - Propriedades físicas do Cambissolo Háplico e do Neossolo Flúvico.

\begin{tabular}{|c|c|c|c|c|c|c|c|c|}
\hline \multirow{2}{*}{$\begin{array}{l}\text { Prof. } \\
\text { Cm }\end{array}$} & Ag & Af & $\mathbf{S}$ & $\mathbf{A}$ & Ds & Dp & $\mathbf{P t}$ & $\begin{array}{c}\text { Classificação } \\
\text { textural }\end{array}$ \\
\hline & \multicolumn{4}{|c|}{ 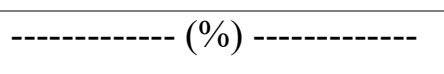 } & \multicolumn{2}{|c|}{--- g.cm$^{-3}---$} & $\%$ & \\
\hline \multicolumn{9}{|c|}{ Cambissolo Háplico } \\
\hline $0-10 \mathrm{~cm}$ & 38 & 30 & 23 & 9 & 1,49 & 2,61 & 42,91 & Franco arenoso \\
\hline $10-20 \mathrm{~cm}$ & 38 & 30 & 21 & 11 & 1,50 & 2,61 & 42,53 & Franco arenoso \\
\hline$>20 \mathrm{~cm}$ & 38 & 30 & 21 & 11 & 1,50 & 2,61 & 42,53 & Franco arenoso \\
\hline \multicolumn{9}{|c|}{ Neossolo Flúvico } \\
\hline $0-10 \mathrm{~cm}$ & 25 & 35 & 27 & 13 & 1,49 & 2,51 & 40,64 & Franco arenoso \\
\hline $10-20 \mathrm{~cm}$ & 25 & 35 & 29 & 11 & 1,48 & 2,54 & 41,73 & Franco arenoso \\
\hline$>20 \mathrm{~cm}$ & 20 & 40 & 29 & 11 & 1,49 & 2,55 & 41,57 & Franco arenoso \\
\hline
\end{tabular}

Prof. - Profundidade; Ag - Areia grossa; Af - Areia fina; S - silte; A - Argila; Ds - Densidade do solo; Dp - Densidade das partículas; Pt (\%) - Porosidade total. Fonte: os autores. 
As análises físicas foram realizadas no Laboratório de Física do Solo pertencente ao Instituto Agronômico de Pernambuco - IPA. Foram utilizados os métodos descritos a seguir para determinação da densidade do solo (Ds), densidade da partícula (Dp), Porosidade Total e análise textural, segundo metodologia da Embrapa (1997).

A análise granulométrica dos solos foi feita pelo método da pipeta (Embrapa, 1997) e definidas as texturas de acordo como o uso do triângulo textural, proposto pela USDA (United States Department of Agriculture) e adaptado pela Sociedade Brasileira de Ciência do Solo.

Nos testes de infiltração foram utilizados infiltrômetros de cilindros concêntricos de aço constituídos de um cilindro externo com $55 \mathrm{~cm}$ de diâmetro interno e $22 \mathrm{~cm}$ de altura e um cilindro interno com $30 \mathrm{~cm}$ de diâmetro interno e $40 \mathrm{~cm}$ de altura.

Foram selecionados de forma aleatória os locais para os testes em relevo plano para cravar os cilindros em áreas com ocorrências dos solos citados. O uso de dois cilindros é necessário para que apenas a água do anel externo tenha um movimento tanto na direção vertical como na horizontal, funcionando como bordadura, garantido que a água colocada no cilindro interno, onde serão feitas as medições, infiltre apenas na direção vertical, como ocorre com a infiltração decorrente de uma precipitação. Na colocação dos cilindros, a vegetação gramínea foi aparada rente ao solo com uma tesoura, para não perturbar a estrutura da camada superficial do solo.

No primeiro momento, o cilindro de maior diâmetro foi cravado até aproximadamente $10 \mathrm{~cm}$ de sua altura, servindo para direcionar a infiltração da água verticalmente e horizontal no solo e utilizando-se um nível de bolha para garantir que o cilindro não ficasse inclinando enquanto o mesmo era cravado no solo.

Em seguida, foi cravado o cilindro interno, seguindo o mesmo procedimento. Depois colocou-se uma régua no cilindro interno e água no cilindro externo acima da linha interna. Posteriormente, foi adicionada água no cilindro interno e disparado o cronômetro nesse instante, dando-se início ao teste, devendo ser lida e registrada a altura inicial da lâmina de água. A altura da lâmina foi mantida aproximadamente constante (entre 15 e $17 \mathrm{~cm}$ ) pela reposição da água infiltrada durante o teste.

Em tempos previamente estabelecidos, registrados num quadro de anotações, foi realizada a leitura da altura da lâmina de água no cilíndro interno, na marca de referência existente no suporte da régua. Procurou-se evitar a movimentação da régua, para se garantir o 
correto registro da variação da altura da lâmina de água no interior do cilindro interno. O teste encerrou-se quando foram obtidas três leituras consecutivas com os mesmos valores.

Os dados coletados em campo foram ajustados à uma equação matemática para expressar a variação da infiltração da água no solo ao longo do tempo. Para tal, utilizou-se a equação empírica de Horton, descrita por Verma (1982), tendo em vista que essa equação assume que a infilltração inicia com uma taxa $f_{0}$ e decresce exponencialmente com o tempo $t$.

$f_{p}=f_{c}+\left(f_{0}-f_{c}\right) e^{-k t}$

Onde: $f_{p}$ - potencial de infiltração no tempo $\mathrm{t}\left(\mathrm{cm} \cdot \mathrm{h}^{-1}\right) ; t$ - tempo transcorrido desde o início do processo de infiltração; $f_{0}-$ taxa de infiltração inicial (tempo $\mathrm{t}=0$ ); $f_{c}-$ taxa de infiltração final, alcançada quando a umidade do solo está próxima da saturação; $k$ - taxa de decaimento constante da taxa de infiltração, dependente das propriedades hidráulicas do solo.

A segunda equação utilizada foi o modelo de Kostiakov, mais simples que a de Horton, pois refere-se a uma equação potencial ajustada para se estimar a infiltração ou a taxa de infiltração em função do tempo. Tal equação possui limitações podendo não ser aplicada a outros tipos de solo e condições de umidade inicial diferentes das condições em que os parâmetros foram determinados.

$I=K t^{\alpha}$

Onde: I - infiltração $\left(\mathrm{cm} \cdot \mathrm{h}^{-1}\right) ; \mathrm{k}$ - constante que depende do solo; $\alpha$ - constante que dependente do solo e de suas condições iniciais; $\mathrm{t}$ - tempo de infiltração (h). Os parâmetros da equação da infiltração foram definidos pelo método da regressão linear.

Os cálculos das equações foram realizados em programa estatístico utilizando-se a análise de regressão pelo método dos mínimos quadrados. Os dados da infiltração obtidos em campo para os dois tipos de solos, no período seco e chuvoso, foram submetidos à estatística descritiva e teste de normalidade de Shapiro-Wilk.

\section{RESULTADOS E DISCUSSÕES}

No período seco, a capacidade de infiltração inicial para o Cambissolo Háplico, foi de $39,75 \mathrm{~cm} \cdot \mathrm{h}^{-1}$, e $23,44 \mathrm{~cm} \cdot \mathrm{h}^{-1}$ para o Neossolo Flúvico. Semelhantemente, no período chuvoso o Cambissolo apresentou superioridade na capacidade de infiltração com $24,84 \mathrm{~cm} \cdot \mathrm{h}^{-1}$ contra $24,09 \mathrm{~cm} \cdot \mathrm{h}^{-1}$ do Neossolo (Figura 1). 


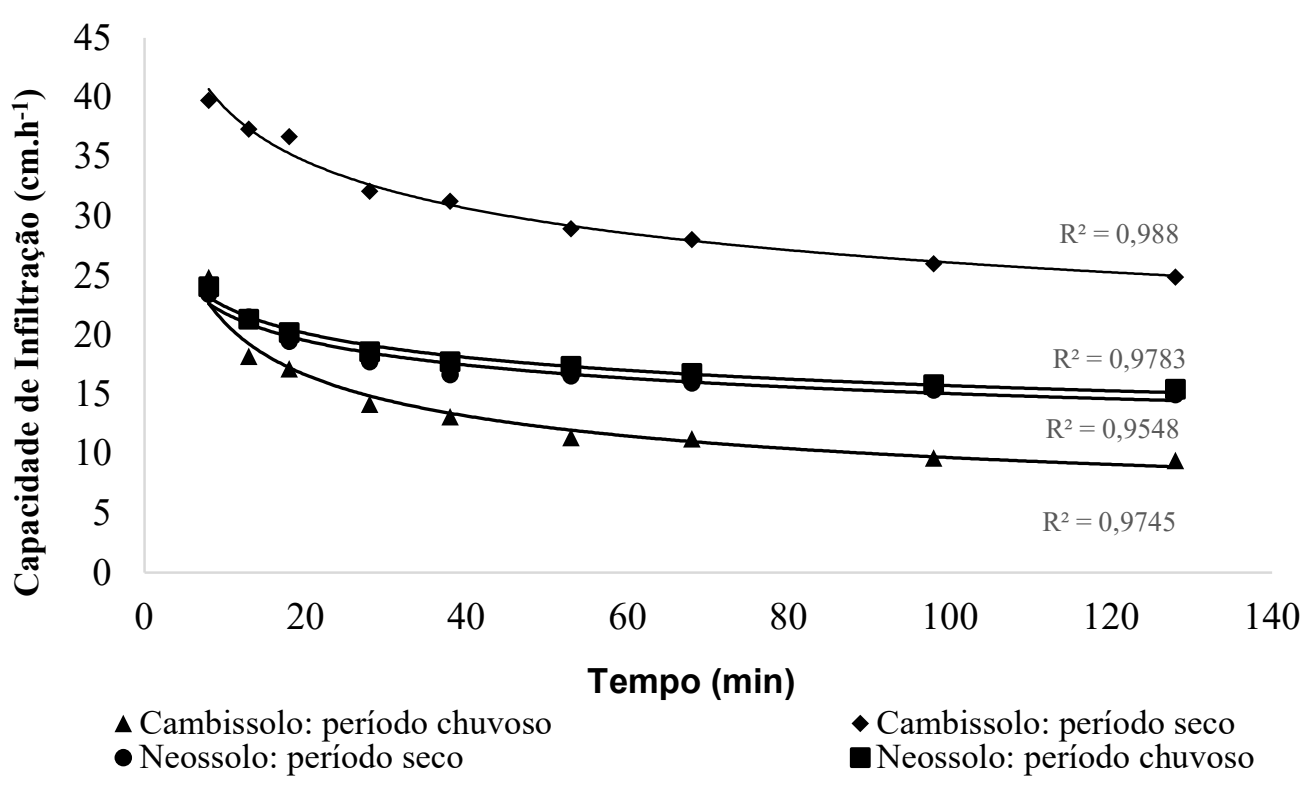

Figura 1.- Capacidade de infiltração $(\mathrm{cm} / \mathrm{h})$ em função do tempo $(\mathrm{min})$ para o Cambissolo Háplico e Neossolo Flúvico nos períodos seco e chuvoso.

A infiltração acumulada mostrou uma superioridade também para o Cambissolo Háplico alcançando um valor final de $53,09 \mathrm{~cm} \cdot \mathrm{h}^{-1}$, com relação ao Neossolo Flúvico 32,03 $\mathrm{cm} \cdot \mathrm{h}^{-1}$ para o período seco, assim como para o Neossolo $\left(33,00 \mathrm{~cm} \cdot \mathrm{h}^{-1}\right)$ e Cambissolo $(20,20$ $\mathrm{cm} \cdot \mathrm{h}^{-1}$ ) no período chuvoso (Figura 2 ).

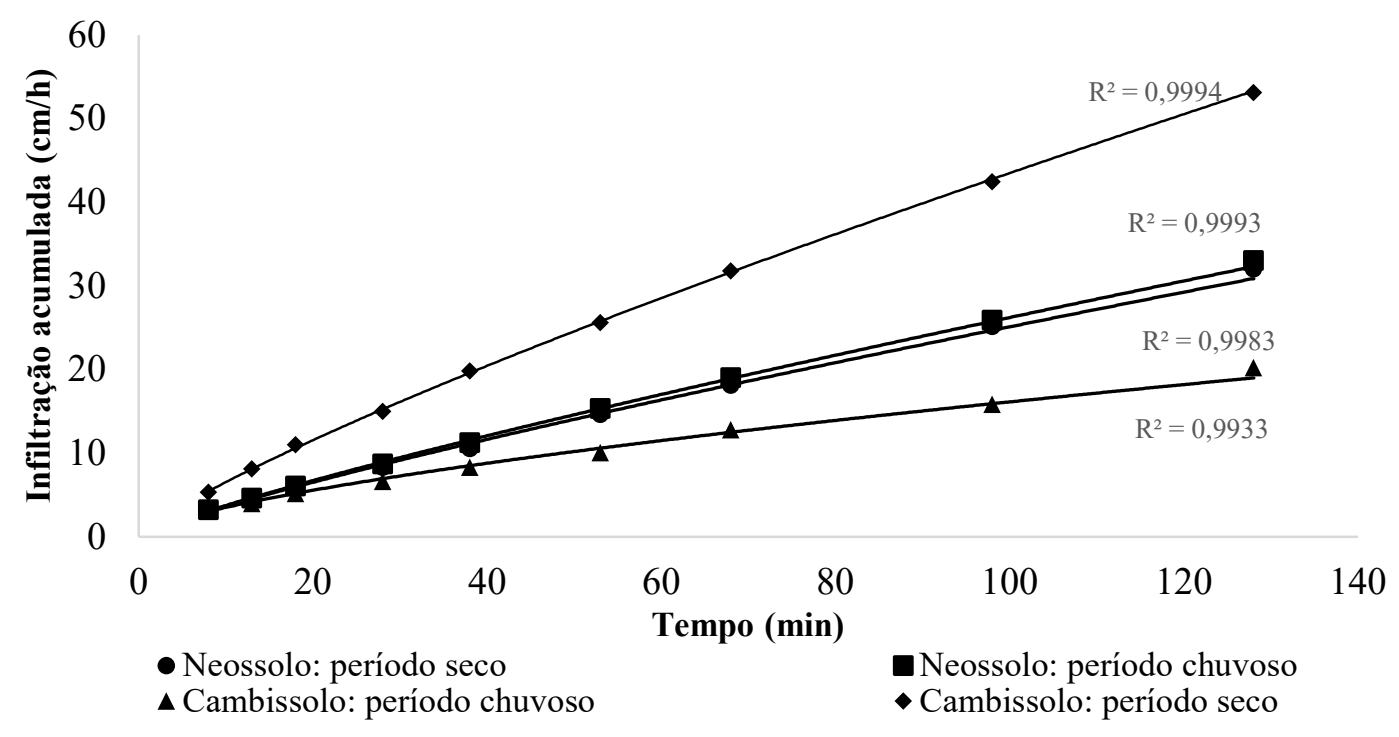

Figura 2.- Infiltração acumulada $(\mathrm{cm} / \mathrm{h})$ em função do tempo ( $\mathrm{min})$ para o Cambissolo Háplico e Neossolo Flúvico no período seco e chuvoso. 
A média da capacidade de infiltração se mostrou superior para o tratamento Cambissolo para o período seco (T2), e o inferior para o Neossolo no período seco (T4), com coeficientes de variação $16,64 \%$ e $16,18 \%$ e desvio padrão de 5,27 e 2,91, respectivamente (Tabela 2).

Tabela 2.- Estatística descritiva para os quatro tratamentos estudados.

\begin{tabular}{ccccccc}
\hline \multirow{2}{*}{ Tratamentos } & Média & $\mathrm{M}$ & $\mathrm{S}^{2}$ & $\mathrm{~S}$ & $\mathrm{CV} \%$ & $\mathrm{SW}$ \\
\hline T 1 & & & & & & Sig. \\
T 2 & 31,67 & 31,26 & 27,73 & 5,27 & 16,64 & 0,587 \\
T 3 & 18,24 & 17,57 & 7,03 & 2,65 & 14,53 & 0,490 \\
T 4 & 17,98 & 16,68 & 8,47 & 2,91 & 16,18 & 0,186
\end{tabular}

T1 - Cambissolo Háplico no período chuvoso; T2 - Cambissolo Háplico no período seco; T3 - Neossolo Flúvico no período chuvoso; T4 - Neossolo Flúvico no período seco; M - Mediana; S² - Variância; S - Desvio Padrão; CV - Coeficiente de Variação; SW - Teste de Shapiro-Wilk; Sig. - P valor $\geq 0,05$ significância.

Para Oliveira et al. (1992), os Cambissolos são originados dos mais diversos materiais de origem e encontrados sob diversas condições climáticas, apresentando textura que varia de franco-arenosa até argilosa. Ainda segundo os mesmos autores os Neossolos podem ser encontrados principalmente nas margens de cursos d’água, conhecidos como solos Aluviais, ou seja, pouco evoluídos (depósitos aluviais recentes), encontrando-se normalmente próximos dos Cambissolos de origem fluvial e os solos Hidromórficos.

Apesar dos solos abordados no presente estudo serem solos jovens, o Cambissolo é mais desenvolvido e um pouco mais profundo que o Neossolo (Resende et al., 2007; Bonna, 2011). Possivelmente estas condições favorecem a sua maior capacidade de infiltração no ambiente semiárido no período seco. No entanto, essa superioridade não se manteve similar no período chuvoso, podendo ser devido à maior porcentagem de argila nas camadas mais profundas deste solo, aliado a uma prévia umidade do solo e, consequentemente, uma menor taxa de infiltração para este período.

O mesmo comportamento não ocorre no Neossolo Flúvico, pois o mesmo é bastante arenoso e não consegue reter umidade, apresentando, portanto, o mesmo comportamento quanto à capacidade de infiltração, independentemente do período.

Os modelos se mostraram eficazes na explicação da capacidade de infiltração para o Cambissolo Háplico e Neossolo Flúvico. Na tabela 3, o período seco foi melhor representado 
pela equação do modelo de Horton, tanto para o Cambissolo Háplico $\left(\mathrm{r}^{2} 0,99\right)$, quanto para o Neossolo Flúvico $\left(\mathrm{r}^{2} 0,98\right)$ com erros de 5,5\% e 3,0\%, respectivamente. Para o período chuvoso o de Kostiakov se mostrou superior com $\mathrm{r}^{2}$ 0,98 para o Neossolo Flúvico, ou seja, explicando $98 \%$ da variância experimental e ${ }^{2}$ 0,97 para o Cambissolo Háplico, com erros do modelo de apenas $2,5 \%$ e $6,4 \%$, respectivamente.

Tabela 3 - Equações obtidas através dos modelos de Horton e Kostiakov (períodos seco e chuvoso), coeficientes de determinação $\left(\mathrm{R}^{2}\right)$ e o erro percentual (\%).

\begin{tabular}{|c|c|c|c|c|c|c|}
\hline \multirow[b]{2}{*}{ Tratamento } & \multirow[b]{2}{*}{ Modelo } & \multicolumn{5}{|c|}{ Parâmetros de Infiltração } \\
\hline & & VI & Vf & $\mathrm{Y}$ & $\mathrm{R}^{2}$ & Sxy $(\%)$ \\
\hline \multicolumn{7}{|c|}{ Período Chuvoso $\left(\mathrm{cm} \cdot \mathrm{h}^{-1}\right)$} \\
\hline \multirow{2}{*}{$\mathrm{CH}$} & Horton & 25,40 & 17,44 & $\mathrm{Y}=37,706 \mathrm{e}^{-0,029 \mathrm{x}}$ & 0,87 & 13,4 \\
\hline & Kostiakov & 25,41 & 17,43 & $Y=50,077 x^{-0,365}$ & 0,97 & 6,4 \\
\hline \multirow{2}{*}{$\mathrm{NF}$} & Horton & 23,34 & 15,29 & $Y=24,235 \mathrm{e}^{-0,032 x}$ & 0,92 & 4,8 \\
\hline & Kostiakov & 21,84 & 15,30 & $Y=32,514 x^{-0,159}$ & 0,98 & 2,5 \\
\hline \multicolumn{7}{|c|}{ Período Seco $\left(\mathrm{cm} \cdot \mathrm{h}^{-1}\right)$} \\
\hline \multirow{2}{*}{$\mathrm{CH}$} & Horton & 40,70 & 24,95 & $\mathrm{Y}=49,124 \mathrm{e}^{-0,050 \mathrm{x}}$ & 0,99 & 5,5 \\
\hline & Kostiakov & 39,91 & 25,19 & $Y=58,140 x^{-0,173}$ & 0,98 & 2,2 \\
\hline \multirow{2}{*}{ NF } & Horton & 23,44 & 15,01 & $Y=26,231 \mathrm{e}^{-0,047 x}$ & 0,98 & 3 \\
\hline & Kostiakov & 22,19 & 15,03 & $Y=32,552 x^{-0,169}$ & 0,96 & 3,5 \\
\hline
\end{tabular}

Trat - Tratamento; CH - Cambissolo Háplico; NF - Neossolo Flúvico; VI - velocidade de infiltração média; Vf - velocidade de infiltração final; Sxy - Erro percentual do modelo.

Apesar da superioridade do modelo de Horton, para o período seco em ambos os solos, o modelo de Kostiakov também conseguiu descrever bem o comportamento da taxa de infiltração para este período, tanto para o Cambissolo Háplico $\left(\mathrm{r}^{2} 0,98\right)$, quanto para o Neossolo Flúvico ( $\left.\mathrm{r}^{2} 0,96\right)$, com erros que não atingiram $4 \%$.

Nas figuras 3 e 4, podem ser vistas as representações das taxas de infiltração tanto para o Cambissolo Háplico quanto para o Neossolo Flúvico no período chuvoso, representando os modelos de Horton e Kostiakov. 


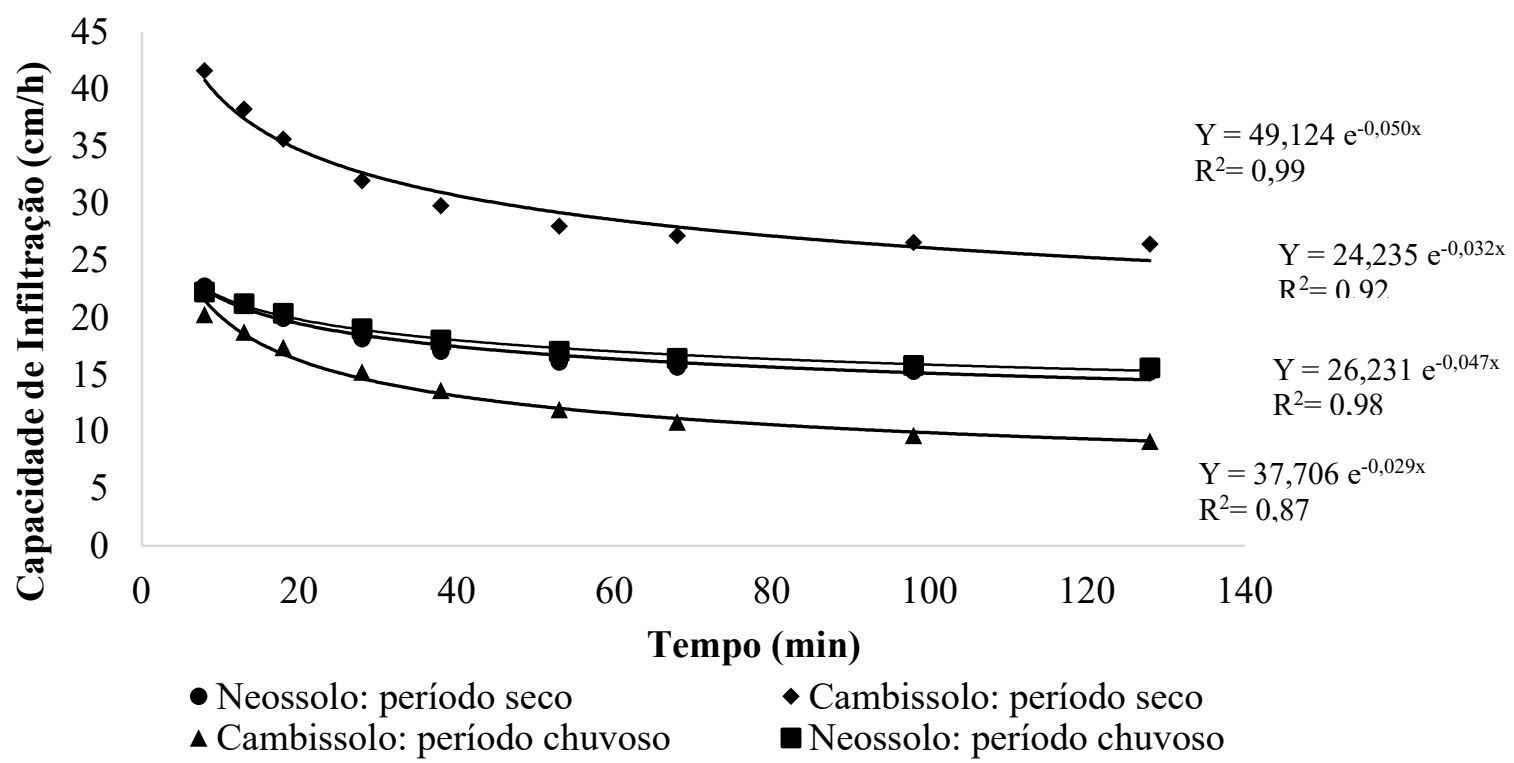

Figura 3.- Modelo de predição de Horton aplicado à capacidade de infiltração de água em Cambissolo Háplico e Neossolo Flúvico para os períodos seco e chuvoso.

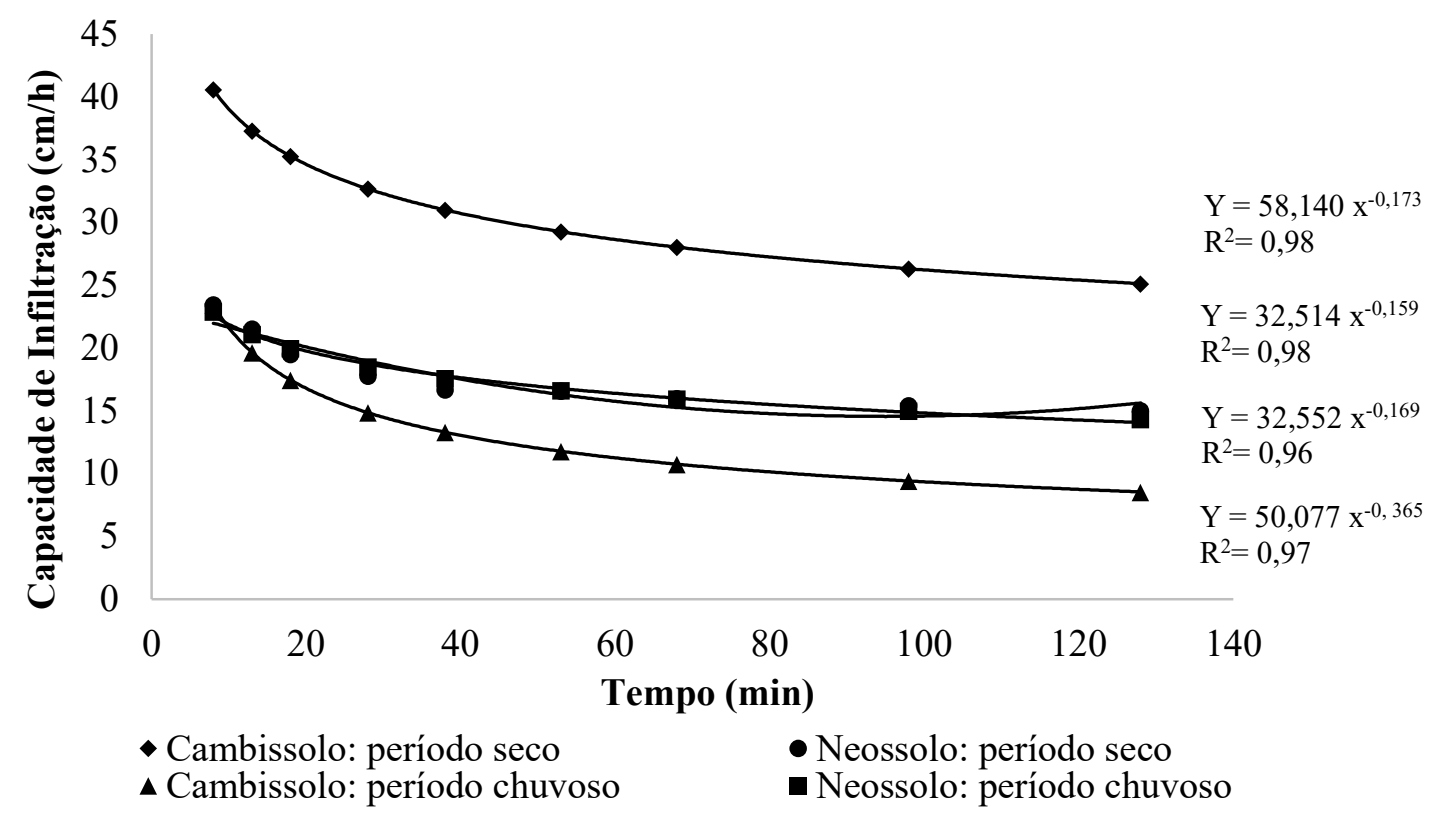

Figura 4.- Modelo de predição de Kostiakov aplicado à capacidade de infiltração de água no Cambissolo Háplico e Neossolo Flúvico para o período seco e chuvoso.

Em estudos com tratamentos distintos, porém com o mesmo método do anel duplo, Silva et al. (2017) e Cunha et al. (2015) obtiveram uma melhor estimativa da capacidade de infiltração, com a utilização dos modelos de Kostiakov. Em contrapartida Paixão et al. (2009) e Almeida et al. (2014) apontaram a equação de Horton com o melhor desempenho. 


\section{CONCLUSÃO}

A capacidade de infiltração do Cambissolo Háplico se mostrou superior em relação ao Neossolo Flúvico, podendo estar relacionada às características físicas que influenciam na maior retenção de umidade no solo independentemente da época da precipitação local e uso do solo distintos em ambas as áreas.

Tanto a equação de Kostiakov como a de Horton podem ser usadas para estimar a taxa final de infiltração do solo in situ no semiárido. Porém a equação de Kostiakov apresentou os melhores coeficientes de determinação para ambos os solos em épocas distintas, além dos menores erros dos modelos.

\section{REFERÊNCIAS BIBLIOGRÁFICAS}

ABDULKADIR, A.; WUDDIVIRA, M. N.; ABDU, N. AND MUDIARE, O.J. Use of Horton Infiltration Model in Estimating Infiltration Characteristics of an Alfisol in the Northern Guinea Savanna of Nigeria. Journal of Agricultural Science and Technology A1, p.925931, 2011.

AHUJA, L.R.; NANEY, J.W.; GREEN, R.E.; NIELSEN, D.R. Macroporosity to characterize spatial variability of hydraulic conductivity and effects of land management. Soil Science Society of America. Journal, Madison, v.48, p.699-702, 1984.

AlAGNA, V.; BAGARELlO, V.; DI PRIMA, S.; IOVINO, M. Determining hydraulic properties of a loam soil by alternative infiltrometer techniques. Hydrol. Process. v. 30, p. 263-275, 2016. DOI: http://dx.doi.org/10.1002/hyp.10607.

ALLEGRE, J.C., D.K. CASSEL, AND D.E. BRANDY. Effects of land clearing on subsequent management on soil physical properties. Soil Sci. Soc. Am. J. v.50, p. 1379-1384. 1986.

ALMEIDA, A. Q.; RIBEIRO, A.; RODY, Y. P.; SILVA, W. C. M.; LEITE, F. P. Modeling of water infiltration in soil cultivated with Eucalyptus and pasture. Rev. Caatinga, v. 27, n. 1, p. $148-153,2014$.

APAC - Agência Pernambucana de Águas e Clima. Monitoramento pluviométrico.

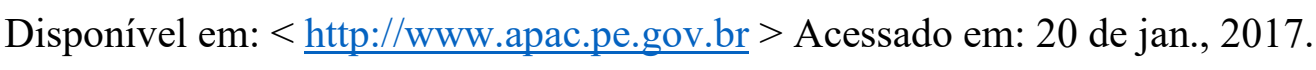


ASTM. Standard test method for infiltration rate of soils in field using double-ring infiltrometer. Annual Book of ASTM Standards 04.08. Amer. Soc. Testing Materials, West Conshohocken, PA. 2003.

BAGARELlO, V.; BAIAMONTE, G.; CASTELlini, M. DI PRIMA, S.; LOVINO, M. A comparison between the single ring pressure infiltrometer and simplified falling head techniques. Hydrol. Process., v.28, p.4843-4853, 2014. DOI: http://dx.doi.org/10.1002/hyp.9980

BERNARDO, S.; SOARES, A. A.; MANTOVANI, E. C. Manual de irrigação. 8.ed. Viçosa: Ed. UFV, p. 611, 2006.

BERNARDO, S. Manual de irrigação. 6 ed. Viçosa: UFV - imprensa Universitária, p. 657, 1995.

BLACKWELL, P.J., M.A. WARD, R.N. LEFEVRE, AND D.J. COWAN. Compaction of a swelling clay soil by agricultural traffic:effects upon conditions for growth of winter cereals and evidence for some recovery of structure. J. Soil Sci., v.36, p.633-650. 1985.

BONNA, J. L. Mapeamento pedológico e de suscetibilidade erosiva no alto córrego prata (Ouro Preto-MG). Mestrado em geografia, universidade federal de minas gerais, 133p. 2011. BOUWER, H. Intake Rate: Cylinder infiltrometer. in: Methods of Soil Analysis. A. Klute, ed. ASA Monograph 9. ASA. Madison, WI., p.825-843, 1986.

BRANDÃO, V. S.; CECÍLIO, R. A.; PRUSKI, F. F.; SILVA, D. D. Infiltração da água no solo. Ed: UFV, $3^{\mathrm{a}}$ ed. Atual e ampl. p.120, 2006.

CANTALICE, J. R. B.; MELO, R. O.; SILVA, Y. J. A. B.; CUNHA FILHO, M.; ARAÚJO, A. M.; VIEIRA, L. P.; BEZERRA, S. A.; BARROS JÚNIOR, S. A.; SINGH, V. P. Hydraulic roughness due to submerged, emergent and flexible natural vegetation in a semiarid alluvial channel. Journal of Arid Environments, 114, 2015, p.1-7. DOI: http://dx.doi.org/10.1016/j.jaridenv.2014.10.012.

CARDURO, F.A.; DORFMAN, R. Manual de ensaios de laboratório e campo para irrigação e drenagem. Brasília: PRONI/MA, p. 216, 1988. 
CARVAlHO, R. P.; DANIEL, O.; DAVIDE, A. C.; SOUZA, F. R. Atributos físicos e químicos de um neossolo quartzarênico Sob diferentes sistemas de uso e manejo. Revista Caatinga, v. 28, n. 1, p. 148-159, 2015.

CASTELLANO, M. J.; VALONE, T. J. Livestock, soil compactation and water infiltration rate: evaluating a potencial desertification recovery mechanism. J. of Arid Environments, v. 27, n. 1, p. 97-108, 2007. DOI: http://dx.doi.org/10.1016/j.jaridenv.2007.03009.

CECÍLIO, R. A. et al. Substituição dos parâmetros do modelo de Green-Ampt-MeinLarson para estimativa da infiltração em alguns solos do Brasil. Revista Brasileira de Ciência do Solo, Viçosa, v. 31, n. 5, p. 1141-1151, 2007.

CECÍliO, R. A.; SILVA, D. D.; PRUSKI, F. F.; MARTINEZ, M. A. Modelagem da infiltração de água no solo sob condições de estratificação utilizando-se a equação de GreenAmpt. Rev. Brasileira Engenharia Agrícola e Ambiental, v.7, p.415-422, 2003.

CHANDRAKANT, L.; JEJURKAR; RAJURKAR, M. P. An investigational approach for the modellingof infiltration process in a clay soil. J. of civil engineering, v. 19, n. 6, p. 19161921, 2015. DOI: http://dx.doi.org/10.1007/s12205-014-0149-3.

CHARTIER, M. P.; ROSTAGNO, C. M.; PAZOS, G. E. Effects of soil degradation on infiltration rates in grazed semiarid rangelands of northeastern Patagonia, Argentina. J. of Arid Environments, v. 75, n. 7, p. 656-661, 2011. DOI: http://dx.doi.org/10.1016/j.jaridenv.2011.02.007.

CHEN, L.; YAUN, Z.; SHAO, H.; WANG, D.; MU, X. Effects of thinning intensities on soil infiltration and water storage capacity in a Chinese pine-oak mixed forest. The Scientific World J., n. 1, p. 268157 - 268157, 2014. DOI: http://dx.doi.org/10.1155/2014/268157.

CHOWDARY, V. M.; DAMODHARA RAO, M.; JAISWAL, C. S. Study of infiltration process under different experimental conditions. Science Direct, v. 83, n. 1-2, p.69-78, 2006. DOI: http://dx.doi.org/10.1016/j.agwat.2005.09.001.

CPRM - Serviço Geológico do Brasil Projeto cadastro de fontes de abastecimento por água subterrânea. Diagnóstico do município de Serra Talhada, estado de Pernambuco. Recife: CPRM/PRODEEM, p.12, 2005. 
COSTA, Y. T.; RODRIGUES, S. C. Efeito do fogo sobre vegetais e solo a partir de estudo experimental em ambiente de cerrado. Revista do Departamento de Geografia, v.30, p. 149 $-165,2015$.

CUNHA, J. L. X. L.; COELHO, M. E. H.; ALBUQUERQUE, A. W.; SILVA, C. A.; SILVA JÚNIOR, A. B.; CARVALHO, I. D. E. Water infiltration rate in Yellow Latosol under different soil management systems. Rev. Brasileira de Engenharia Agrícola e Ambiental. v.19, n.11, p.1021-1027, 2015. DOI: http://dx.doi.org/10.1590/18071929/agriambi.v19n11p1021-1027.

DIAMOND, J.; SHANLEY, T. Infiltration Rate Assessment of Some Major Soils. Irish Geography, v.36, n.1, p. 32-46, 2003.

DUNKERLEY, D. An approach to analysing plot scale infiltration and runoff responses to rainfall of fluctuating intensity. Hydrol. Process. v.31, p.191-206, 2017. DOI: http://dx.doi.org/10.1002/hyp.10990.

EBEL, B. A.; MOODY, J. A. Synthesis of soil-hydraulic properties and infiltration timescales in wildfire-affected soils. Hydrol. Process. v.31, p.324-340, 2017. DOI: http://dx.doi.org/10.1002/hyp.10998.

EMBRAPA - Empresa Brasileira de Pesquisa Agropecuária. Sistema Brasileiro de Classificação de Solos. 2 ed. Rio de Janeiro, p.306, 2006.

EMBRAPA - Empresa Brasileira de Pesquisa Agropecuária. Cartilhas: Solos do Nordeste. p.8, $2004 . \quad$ Disponível:

http://ainfo.cnptia.embrapa.br/digital/bitstream/item/114582/1/FOLDER-SOLOS-DO-NEversao-final.pdf > Acessado em: 20 de fev., 2017.

EMBRAPA - Empresa Brasileira de Pesquisa Agropecuária. Levantamento de reconhecimento de baixa e média intensidade dos solos do Estado de Pernambuco. Rio de Janeiro: Embrapa Solos. Boletim de pesquisa n.11, p.382, 2000.

EMBRAPA - Empresa Brasileira de Pesquisa Agropecuária. Manual de métodos de análise de solo. Centro Nacional de Pesquisa de Solos, 2. ed. rev. atual. - Rio de Janeiro, p. 212, 1997. FISCHER, C.; ROSCHER, C.; JENSEN, B.; EISENHAUER, N.; BAADE, J.; ATTINGER, S.; SCHEU, S.; WEISSER, W. W.; SCHUMACHER, J.; HILDEBRANDT, A. How do 
Eartworms, Soil Texture and Plant Composition Affect Infiltration along an Experimental Plant Diversity Gradient in Grassland? Plos one, v.9, n.6, p.1-12, 2014. DOI: https://doi.org/10.1371/journal.pone.0098987.

FRANZLEBBERS, A. J. Water infiltration and soil structure related to organic matter and its stratification with depth. Soil \& Tillage Research, v.66, p. 197-205, 2002.

GAGELER, R.; BONNER, M.; KIRCHHOF, G.; AMOS, M.; ROBINSON, N.; SCHMIDT, S.; SHOO, L. P. Early Response of Soil Properties and Function to Riparian Rainforest Restoration. Plos one, v.9, n.8, p.1-8, 2014. DOI: https://doi.org/10.1371/journal.pone.0104198.

GONÇALVES, F. C.; MORAES, M. H. Porosidade e infiltração de água do solo sob diferentes sistemas de manejo. Irriga, v.17, n.3, p.337-345. 2012.

GREGORY, J.H., DUKES, M.D., MILLER, G.L.; JONES, P.H. Analysis of double-ring infiltration techniques and development of a simple automatic water delivery system. Applied Turfgrass Science. v.2, n.1, 2005. DOI: http://dx.doi.org/10.1094/ATS-2005-0531-01-MG.

HARTGE, H. K. The problem of compaction on agricultural lands. Applied Geography and Development, v.32, p. 44-50, 1988.

HILLEL, D. Introduction to soil physics. San Diego: Academic Press, INC, p., 392, 1982.

HILLEL, D. Fundamentals of soil physics. Academic Press Inc., New York, USA. p.,413, 1980.

IBGE - Instituto Brasileiro de Geografia e Estatística. Manuais técnicos da vegetação brasileira. $2^{\mathrm{a}}$ ed. revisa e ampliada, n.1, 2012.

IBGE - Instituto Brasileiro de Geografia e Estatística. 2016. Disponível em: < http://www.ibge.gov.br/home/presidencia/noticias/21052004biomashtml.shtm $>$ Acessado em: 6 de abr., 2017.

JOHNSON, A. I. A field method for measurement of infiltration. General ground-water techniques: geological survey water-supply paper. United states government printing office, p.31, 1963. 
LAI, J. and REN, L. Assessing the size dependency of measured hydraulic conductivity using double ring infiltrometers and numerical simulation. Soil Sci. Soc. Am. J. v.71, p.1667-1675, 2007.

LIBARDI, P. L. Dinâmica da Água no Solo. São Paulo: Editora da Universidade de São Paulo, p.335, 2005.

LIU, H.; LEI, T.W.; ZHAO, J.; YUAN, C. P.; FAN, Y. T.; QU, L. Q. Effects of rain fall intensity and antecedente soil water content on soil infiltrability under rainfall conditions using the run off-on-out method. J. of Hydrology, v. 396, n. 1-2, p. 24-32, 2011. DOI: http://dx.doi.org/10.1016/j.jhydrol.2010.10.028.

LUCIANO, R. V.; BERTOL, I.; BARBOSA, F. T.; KUSTZ, C.; FAYAD, J. A. Propriedades físicas e carbono orgânico do solo sob plantio direto comparados à mata natural, num Cambissolo Háplico. Revista de Ciências Agroveterinárias. Lages, v.9, n.1, p. 09-19, 2010. MANCUSO, M. A.; FLORES, B. A.; ROSA, G. M.; SCHROEDER, J. K.; PRETTO, P. R. P. Características da taxa de infiltração e densidade do solo em distintos tipos de cobertura de solo em zona urbana. Rev. Monografias Ambientais - REMOA, v. 14, n. 1, Edição Especial, p. 2890 - 2998, 2014. DOI: http://dx.doi.org/10.5902/2236130810932.

MANTOVANI, E. C.; BERNARDO, S.; PALARETTI, L. F. Irrigação: princípios e métodos. 3 ed. Viçosa: UFV, p.355, 2009.

MANTOVANI, E. C.; BERNARDO, S.; PALARETTI, L. F. Irrigação: princípios e métodos. Viçosa: UFV, p. 318, 2006.

MAZAHERI, M. R.; MAHMOODABADI, M. Study oninfiltration rate based on primary particle size distribuition data inarid and semiarid region soils. J. Geosci, v. 5, n. 5, p.10391046, 2012. DOI: http://dx.doi.org/10.1007/s12517-011-0497-y.

MESHIGI, A.; CHUI, T. F. M. Analysing tension infiltrometer data from sloped surface using two-dimensional approximation. Hydrol. Process. 28, 744-752 (2014). DOI: http://dx.doi.org/10.1002/hyp.9621.

MIN - Ministério de Integração Nacional. Nova delimitação do semiárido brasileiro. Cartilha, p.35. Disponível em: < http://www.mi.gov.br/c/document_library/get_file?uuid=0aa2b9b5aa4d-b55-a6e1-82faf0762763\&groupId=24915 > Acessado em: abr. 2017. 
MORIN, J.; VAN WINKEL, J. The effect of raindrop impact and sheet erosion on infiltration rate and crust formation. Soil Science Society of America Journal, v.60, p.1223-1227, 1996. OLIVEIRA, J. B.; JACOMINE, P. K. T.; CAMARGO, M. N. Classes gerais de solos do Brasil: guia auxiliar para seu reconhecimento. FUNEP, Jaboticabal, p. 201, 1992.

OLORUNFEMI, I. E.; FASINMIRIN, J. T. Land use management effects on soil hydrophobicity and hydraulic properties in Ekiti State, forest vegetative zone of Nigeria. Catena v.155 p.170-182, 2017. DOI: http://dx.doi.org/10.1016/j.catena.2017.03.012.

OLSON, T.C. and SWARTZENDRUBER, D. Model study of the double ring infiltrometer in layered systems. Int. Congr. Soil Sci. Trans. 7th (Madison, Wis.) v.1, p. 441-447, 1960.

OSUJI, G. E.; OKON, M. A.; CHUKWUMA, M.C.; NWARIE, I. Infiltration Characteristics of Soil under Selected Land Use Practices in Owerri, Southeastern Nigeria. World J. of Agriccultural Sciences., v.6, n.3, p.322 - 326, 2010.

PAGLIAI, M.; VIGNOZZI, N.; PELLEGRINI, S. Soil structure and the effect of management practices. Soil \& Tillage Research, v.79, p.131-143, 2004. DOI: http://dx.doi.org/10.1016/j.still.2004.07.002.

PAIXÃO, F. J. R.; ANDRADE, A. R. S.; AZEVEDO, C. A. V.; COSTA, T. L.; GUERRA, H. O. C. Ajuste da curva de infiltração por meio de diferentes equaçãos empíricos. Pesq. Aplicada \& Agrotecnologia. v.2, n.1, p. 107-112, 2009.

PHILIPS, C.E. A review of methods for characterization of site infiltration with design recommendations. J. of the Nevana Water Resources Association. v.6, n.1, p.29-46, 2011. PINTO, N. L. S. HOLRZ, A. C. T.; MARTINS, J. A.; GOMIDE, F. L. S. Hidrologia básica. São Paulo: Edgand Blücher, p.278, 1976.

PISCOYA, V. C. Manejo em bacia hidrográfica do riacho Jacu: produção de sedimentos, dimensionamento de faixa de vegetação ciliar e salinidade da água em barragem subterrânea. Tese de Doutorado (Ciência do Solo), Universidade Federal Rural de Pernambuco, Recife, p. $140,2012$.

PRADO, D. As caatingas da América do Sul. In: LEAL, I. R.; TABARELLI, M.; SILVA, J. M. C. Ecologia e conservação da Caatinga. Recife, Universidade Federal de Pernambuco, p. 804, 2003. 
PREVEDELLO, C.L. Física do solo com problemas resolvidos. Ed. SAEAFS. Curitiba, PR, p.446, 1996.

PRUSKI, F. F.; VENDRAME, V.; OLIVEIRA, E. F. de; BALBINO, L. C.; FERREIRA, P. A.; WERLANG, L.; CARVALHO, L.T. Infiltração de água num latossolo roxo. Pesq. agropec. bras., v.32, n.1, 1997.

REICHARDT, K. Água em sistemas agrícolas. São Paulo: Manole. p.188, 1987.

REICHERT, J.M.; VEIGA, M.; CABEDA, M.S.V. Selamento superficial e infiltração de água em solos do Rio Grande do Sul. Rer. Bra. de Ciência do Solo, Campinas, v.16, n.3, p.289298, 1992.

RESENDE, M.; CURI, N.; REZENDE, S. B.; CORRÊA, G. F. Pedologia: base para distinção de ambientes. 5.ed. Lavras, MG: Editora UFLA, 2007. 322p.

SALES, L.E. O.; FERREIRA, M.M.; DE OLIVEIRA, M.S.; CURI, N. Estimativa da Velocidade de Infiltração Básica do Solo. Pesq. agropec. bras., Brasília, v.34, n.11, p.20912095, 1999.

SECO, D. N. Nordeste sertanejo: a região semi-árida mais povoada do mundo. Estudos avançados, v.13, n.35, 1999. DOI: http://dx.doi.org/10.1590/S0103-40141999000200003.

SILVA, N. F.; CUNHA, F. N.; CABRAL FILHO, F. R.; MORAIS, W. A.; CUNHA, E. S.; ROQUE, R. C.; ALVES, D. K. M.; TEIXEIRA, M. B. Método para estimativa da infiltração de água em um latossolo sob plantio direto e convencional. Global Science and Technology, v. 10, n.1, p. 169-176, 2017.

SOUZA, Z. M.; ALVES, M. C. Movimento de água e resistência à penetração em um Latossolo Vermelho distrófico de Cerrado, sob diferentes usos e manejos. Rev. Bra. de Engenharia Agrícola e Ambiental, v.7, n.1, p.18-23, 2003.

SRINIVASAN, K.; POONGOTHAI, S. Assessment of Infiltration rate of a Tank Irrigation Watershed of Wellington reservoir, Tamilnadu, Índia. American J. of Engineering Research. v.2, n.7, p. 41-48, 2013.

STÜRMER, S. L. K.; DALMOLIN, R. S. D.; AZEVEDO, A. C.; PEDRON, F. A.; MENEZES, F. P. Relação da granulometria do solo e morfologia do saprolito com a infiltração 
de água em Neossolos Regolíticos do rebordo do Planalto do Rio Grande do Sul. Ciência Rural, Santa Maria. v. 39, p. 2057-2064, 2009.

THUROW, T.L., W.H. BLACKBURN, AND C.A. TAYLOR JR. Infiltration and interril erosion response to selected livestock grazing strategies, Edwards Plateu, Texas. J. of Range Manag. v.4, n. 4, p. 296-302. 1988.

TOUMA, J.; ALBERGEL, J. Determining soil hydrologic properties from rain simulator or double ring infiltrometer experiments: a comparison. J. of Hydrology, 135: 73-86, 1992.

TRICKER, A.S. The infiltration cylinder: Some comments on its use. J. Hydrol., Amsterdam, v.36, p. 383-391. 1978.

VERMA, S. C. Modified Horton`s Infiltration Equation. J. Hydrol., v.58, p.383-388, 1982.

VOGELMANN, E. S.; EPREVEDELlO, J.; REICHERT, J. M. Origem dos compostos hidrofóbicos e seus efeitos em florestas de Pinus Eucalyptus. Ciência Florestal, v. 25, n. 4, p. 1067-1079, 2015.

VOORHES, W.B. AND M.J. LINDSTROM. Long-term effects of tillage on soil tilth independent on wheel traffic compaction. Soil Sci. Soc. Am. J., v. 48, p.152-156. 1984.

WANG, L.; ZHONG, C.; GAO, P.; XI, W.; ZHANG, S. Soil infiltration characteristics in agroforestry systems and their relationships with the temporal distribution of rainfall o the loess plateau in China. J. Plos one, v. 10, n. 4, 2015. DOI: http://dx.doi.org/10.1371/journal.pone.0124767.

WU, G.; LIU, Y.; YANG, Z.; CUI, Z.; DENG, L.; CHANG, L.; SHI, Z. Root channels to indicate the increase in soil matrix water infiltration capacity of arid reclaimed mine soil. $\mathbf{J}$. of Hydrology, v.546, p.133-139, 2017. DOI: http://dx.doi.org/10.1016/j.jhydrol.2016.12.047. ZONTA, J. H.; MARTINEZ, M. A.; PRUSKI, F. F.; SILVA, D. D.; SANTOS, M. R. Efeito da aplicação sucessiva de precipitação pluviais com diferentes perfis na taxa de infiltração de água no solo. Rev. Brasileira de Ciências do Solo, v. 36, n. 2, p. 377-388, 2012. DOI: http://dx.doi.org/10.1590/S0100-06832012000200007. 